\title{
Discussion on the Importance of Combination with Railway Route Selection and Urban Planning
}

\author{
Wenbo WANG ${ }^{1}$ \\ China Railway First Survey and Design Institute Group Ltd, Lanzhou 730000, \\ China
}

\begin{abstract}
The density of cities in Northwest China is relatively low, and the scale of cities is relatively small compared with the developed areas in Southeast China. In addition, the early urban planning hadn't systematically plan the blue line, red line and purple line in the urban area. These caused designers ignored the influence of urban planning on route selection in the design scheme. With the rapid development of China's economy and the continuous expansion of the city scale, the status of urban planning has become more and more important. Railway engineers need to change their ideas and pay attention to the impact of urban planning on the design scheme. Taking the high-speed railway from Zhongwei to Lanzhou as an example, this paper discusses the relationship between railway route selection and urban planning in the urban built-up area combined with the problems encountered in the design and the principle of urban planning. It is concluded that railway route selection must be closely combined with urban planning. It systematically analyzes how to fully consider the influence of environmental protection, urban land, four lines of urban planning and other factors in the process of railway selection, so as to provide reference for railway route selection in large cities.
\end{abstract}

Keywords. High-speed railway from Zhongwei to Lanzhou, urban planning, railway terminal, route selection, environmental protection

\section{Historical Relationship between Urban Development and Existing Railway}

For a large and medium-sized city, railway is the main way of long-distance transportation. Before China's reform and opening up, due to the limitations of economic development and population scale, the city scale was small in normal conditions. The railway passenger stations were located in the central area of the city, which was convenient for citizen travel. The railway freight stations and freight yards closely related to production and life were arranged in the suburban areas or storage areas; some special railway lines of heavy industry enterprises are arranged around the enterprises. From the perspective of the city scale and planning concept at that time, this layout is reasonable and effective [1-7]. After the reform and opening up, with the rapid development of China's economy, the siphon effect of cities, especially mega cities and regional central cities on the surrounding areas is more and more strong,

\footnotetext{
${ }^{1}$ Corresponding Author, Wenbo Wang, Room 326, No.131 Hezheng Road, Chengguan District, Lanzhou, China; E-mail: 412049210@qq.com.
} 
resulting in the continuous expansion of urban population and scale, so that the original stations and special railway lines located in the outskirts of the city or around enterprises will cut the urban land into multiple blocks, seriously affecting the urban development.

Lanzhou is a typical city affected by this situation. In the early days of the founding of the People's Republic of China to the 1980s, a large number of heavy industrial enterprises were established in Lanzhou. For example, Petrochina Lanzhou oil refining and chemical complex, Petrochina Lanzhou Petrochemical Company, Petrochina Lanzhou Chemical Industry Company and Lanzhou Petrochemical Machinery Plant were all located outside the main urban area of Lanzhou at that time, and their relevant special railway lines hadn't cut the urban area. However, with the development of the city, the special line for enterprises has seriously affected the urban layout and the land use value around the railway.

\section{Influence of Urban Blue Line on Route Selection and Layout of Bridge and Culvert Span}

In the process of new railway line selection, the small spillway have neglected frequently. The designer arranges the bridge span according to the river flow and the width of the existing spillway. For large rivers, such as the Yangtze River, the Yellow River, Heilongjiang and its primary tributaries, as well as rivers with large population gathering areas in the basin, the water conservancy department will require Party A to prepare flood control evaluation report according to the actual situation. In this way, designers often form a thinking set, there's no need to pay attention to small spillways, and the bridge span arranged have not less than the width of the existing spillway or the structure arrangement form of the existing railway. However, in urban areas, especially in large and medium-sized cities, the blue line is defined in the overall planning. The width of blue line is far greater than the current situation.

Taking Lanzhou City as an example, the fourth edition of the urban master plan defines the blue line for all 103 spillways directly flowing into the Yellow River in Lanzhou City, and the width of these blue lines is far greater than the existing width of the spillway. For example ,among the urban spillways involved in Zhong-Lan high-speed railway, the current width of Dajingou spillway is about 9-20m, it have $1-4 \mathrm{~m}$ arch culvert on Dajingou of the existing Lan-Xin railway, it have $1-9 \mathrm{~m}$ arch culvert on Dajingou of the existing bullet train station, and the width of Dajingou blue line defined in the fourth version of overall planning of Lanzhou city is $40 \mathrm{~m}$. The current width of Shengou is about $25 \mathrm{~m}$, it have $1-1 \mathrm{~m}$ circular culvert on Shengou of the existing Shenhu road; it have $2-10.8 \mathrm{~m}$ frame bridge on Shengou of the existing Lan-Xin railway, and it have $2-20 \mathrm{~m}$ box girder bridge on Shengou of the existing Xijin West Road. However, the width of Shengou blue line defined in the overall planning of Lanzhou city is $40 \mathrm{~m}$, which is also far greater than the width of the existing spillway and the aperture of the existing bridge and culvert. The statistics of the urban spillway involved in Zhong-Lan high-speed railway are shown in Table 1: 
Table 1. Spillway statistics of Zhongwei to Lanzhou high-speed railway

\begin{tabular}{|c|c|c|c|c|}
\hline Spillway & $\begin{array}{l}\text { Width of } \\
\text { existing } \\
\text { spillway }\end{array}$ & $\begin{array}{l}\text { Aperture of bridge and culvert with } \\
\text { existing railway / Road on the } \\
\text { spillway }\end{array}$ & $\begin{array}{c}\text { Blue } \\
\text { line } \\
\text { width }\end{array}$ & Design span \\
\hline Xiaojingou & $9-20 \mathrm{~m}$ & $12 \mathrm{~m} \mathrm{~T}$ beam-Lanxin railway & $28 \mathrm{~m}$ & $24 \mathrm{~m} \mathrm{~T}$ beam \\
\hline \multirow[b]{2}{*}{ Dajingou } & \multirow[b]{2}{*}{$10-20 \mathrm{~m}$} & $4 \mathrm{~m}$ arch culvert-Lanxin railway & \multirow[b]{2}{*}{$40 \mathrm{~m}$} & \multirow[b]{2}{*}{$24 \mathrm{~m} \mathrm{~T}$ beam } \\
\hline & & $9 \mathrm{~m}$ arch culvert-Bullet train station & & \\
\hline \multirow[b]{3}{*}{ Shengou } & \multirow[b]{3}{*}{$25 \mathrm{~m}$} & $1 \mathrm{~m}$ circular culvert-Shenhu road & \multirow[b]{3}{*}{$40 \mathrm{~m}$} & \multirow{3}{*}{$\begin{array}{c}32 \mathrm{~m} \mathrm{~T} \text { beam } \\
/ 24+32+32+24 \mathrm{mcon} \\
\text { tinuous rigid-frame } \\
\text { beam }\end{array}$} \\
\hline & & $2-10.8 \mathrm{~m}$ frame bridge-Lanxin railway & & \\
\hline & & 2-20m box girder bridge-Xijin west road & & \\
\hline & & $20 \mathrm{~m} \mathrm{~T}$ beam-Lanxin railway & & \multirow{2}{*}{$\begin{array}{c}29.5 \mathrm{~m} \text { Simply } \\
\text { supported slab } \\
\text { beam } / 32 \mathrm{~m} \text { T beam }\end{array}$} \\
\hline Yuangou & $12 \mathrm{~m}$ & $\begin{array}{l}\text { 2-12m frame bridge -Lanzhou subway } \\
\text { Line } 1\end{array}$ & $28 \mathrm{~m}$ & \\
\hline
\end{tabular}

It can be seen from Table 1. that the designed span is larger than the existing width of the spillway and the aperture of the existing bridge and culvert, the layout of span completely meets the requirements of flood discharge with a 100 year return period. Among them, the flood control evaluation report of Xiaojingou, Dajingou and Yuangou haven't been prepared due to the impact of the change. Setting up $24+32+32+24 \mathrm{~m}$ rigid frame continuous beam bridge across Shengou (station line) and 2-32m $\mathrm{T}$ beam $+1-64 \mathrm{~m}$ tied arch bridge (main line, $32 \mathrm{~m}$ T beam crossing the Shengou).

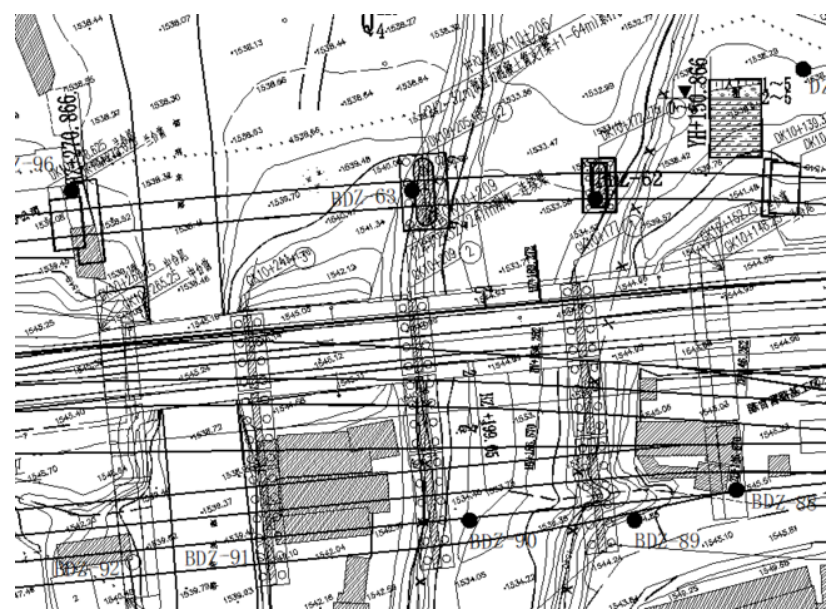

Figure.1 Layout of bridge span on the Shengou

It can be seen that the layout span of Zhong-Lan high-speed railway has greatly optimized the flood discharge conditions of the existing spillway, and the span of the upstream Shenhu road culvert and the downstream Xijin West Road bridge are smaller than the layout span of the railway bridge. However, the layout of the railway bridge span is still smaller than the width of the blue line of the urban master plan, the competent department of water resources hired experts to conduct field survey and required to add the bridge span. In principle, piers should not be arranged within the blue line. However, due to the large number of turnouts arranged on the south station line bridge, the width of the cross bridge direction has reached 49-53m (cross bridge direction variable section), and it is necessary to build multiple shunting transitions in 
amplitude and time, so it is difficult to adjust the layout of span. Therefore, the third-party assessment unit is requested to prepare the flood control assessment report. Although the conclusion of the flood control report is that the bridge layout meets the flood discharge requirements, it is still recommended to adjust the span to arrange the piers outside the width of the blue line.

According to Article 10 of the Management measures for urban blue line (Order No. 145 of the Ministry of construction of the people's Republic of China): construction activities that violate the requirements for the protection and control of the blue line of the city are prohibited; Article 11: all construction activities within the blue line of the city must conform to the approved urban planning; all kinds of buildings and structures are newly built, rebuilt and expanded within the blue line of the city Materials, roads, pipelines and other engineering facilities shall apply to the competent department of construction (competent department of urban and rural planning) for urban planning permission in accordance with the law, and go through relevant procedures in accordance with relevant laws and regulations [8]. According to the Management measures for urban blue line and the above examples, it can be seen that the railway line selection and bridge span in urban area are greatly affected by urban blue line, so it is necessary to collect urban blue line data in the location survey stage of railway projects in urban area, choose railway scheme and bridge span based on the blue line data.

\section{Impact of Environmental Protection on Line Selection}

Different from the field, there are a large number of noise sensitive points in the urban area, such as schools, hospitals, nursing homes, residential areas, etc. The distance between railway and these noise sensitive points must be considered in line selection. Taking the Zhong-Lan high-speed railway as an example, the railway starts from Lanzhou West Railway Station, then goes west along Nanshan Road, passes through the existing Lan-Xin high speed railway at Xiaojingou, then goes up and crosses the existing Lan-Xin railway, and then goes to Chenguanying station along the West Xijin road in parallel with the Lan-Xin railway. There is a large residential area and two schools within the scope of this section. The construction of the existing Lan-Xin railway was affected by the size of the city at early time Limited by the planning concept, and the line is close to residential areas and schools.

The original construction plan of Zhong-Lan high-speed railway passes through this section in the form of bridge (sound screen barrier beam), which reduces the impact on noise sensitive points such as residential areas as much as possible. According to the requirements of the construction unit, the section needs to be rerouted. So the environmental protection is a key consideration.

\subsection{South Double Track Bridge Scheme}

The railway passes through the Lan-Xin High Speed railway under Lijiagou and parallels the Lan-Xin railway to the West. The railway is located at the south side of the existing Lan-Xin railway. 


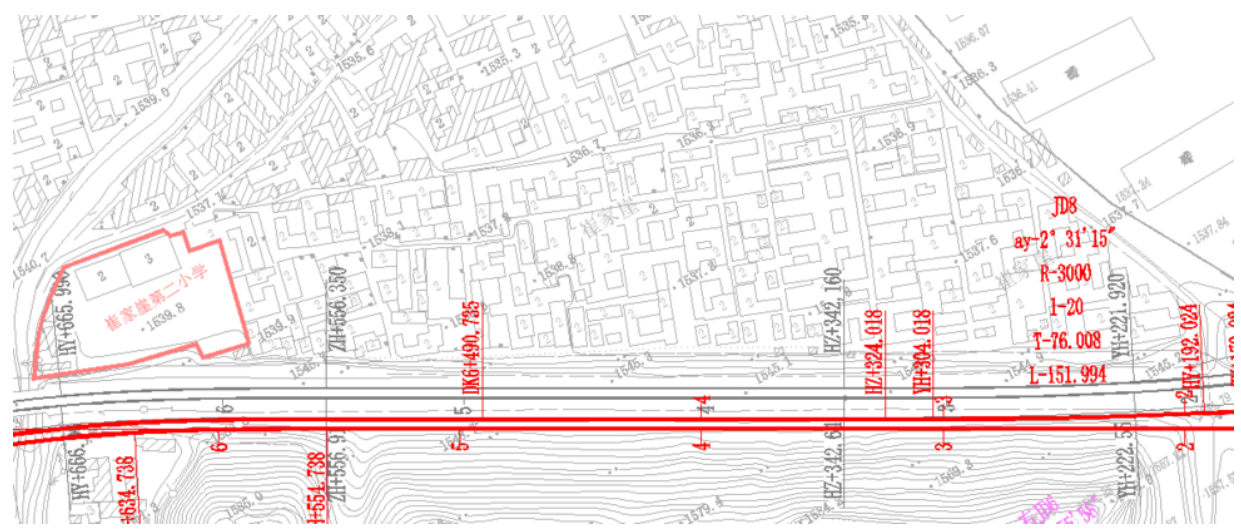

Figure.2 Schematic diagram of bridge on the south side of Lan-Xin railway

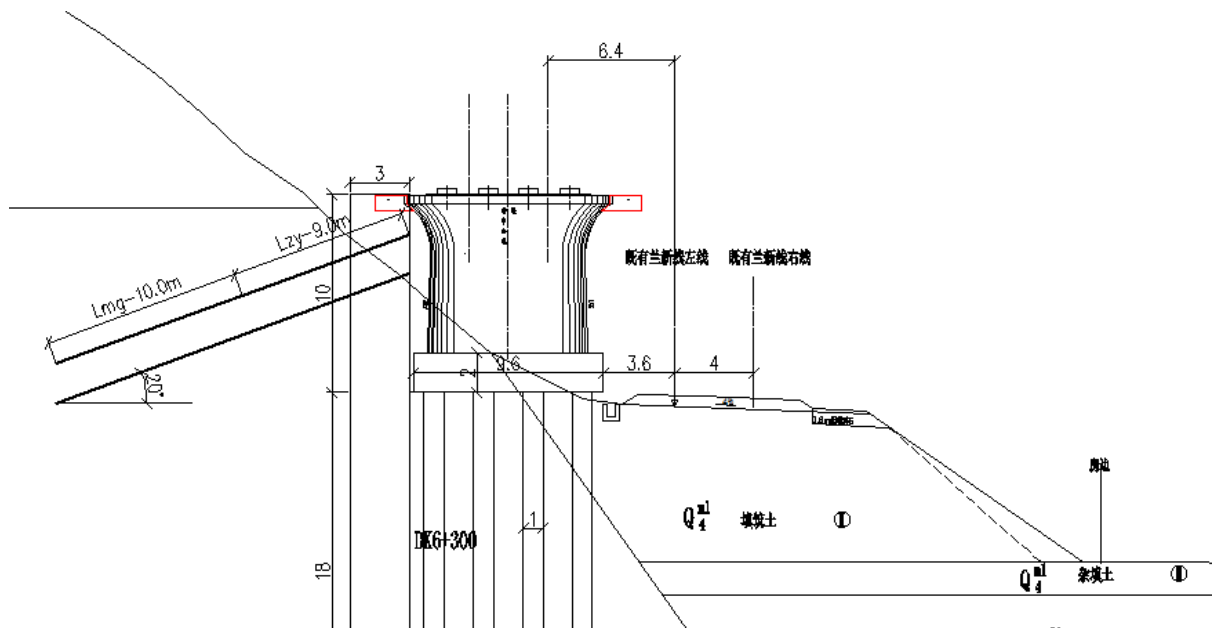

Figure.3 Sectional drawing of Zhong-Lan high-speed railway and Lan-Xin railway

It can be seen from Figure 2 and Figure 3, the Zhong-Lan high-speed railway will be built on the south side of the existing Lan-Xin railway (far away from the residential area), and the bridge will be used for passing through. In this case, most designers think that the new railway is away from the residential area on the side of the existing railway, so it have not affect the residential area and have not need to communicate with the local government and stakeholders.

But in fact, this design concept is wrong and doesn't conform to the relevant laws and regulations of urban planning or departmental regulations. For example, according to Code for design of sound insulation of civil buildings(GB50118-2010), the distance between school outer wall with windows and the railway cannot be less than $300 \mathrm{~m}$. However, the Zhong-Lan high-speed railway is only $25 \mathrm{~m}$ away from Cuijiaya No.2 Primary School, which obviously violates the requirements of the GB50118-2010. Even if the railway adopts noise barrier and other noise suppression equipment, it also needs to measure the noise to meet the requirement of $\leq 40 \mathrm{~dB}$ specified in GB50118. Even if the sound insulation equipment is installed at such a distance, it is difficult to meet this requirement. In addition to the first and second primary schools in Cuijiaya, this section is also a large-scale residential area with a large number of residential 
buildings and community health centers. The noise requirement of residential buildings in the daytime is $\leq 40 \mathrm{~dB}$, especially at night is $\leq 30 \mathrm{~dB}$ [9].

Table 2. Allowable noise table of civil buildings

\begin{tabular}{|c|c|c|c|}
\hline & \multirow[t]{2}{*}{ Room name } & \multicolumn{2}{|c|}{ Allowable noise level (dB) } \\
\hline & & daytime & nighttime \\
\hline \multirow[b]{2}{*}{ School } & $\begin{array}{c}\text { Language classroom and } \\
\text { preview room }\end{array}$ & \multicolumn{2}{|c|}{$\leq 40$} \\
\hline & general classroom & \multicolumn{2}{|c|}{$\leq 45$} \\
\hline \multirow{2}{*}{$\begin{array}{l}\text { High-rise } \\
\text { residential }\end{array}$} & bedroom & $\leq 40$ & $\leq 35$ \\
\hline & The living room & \multicolumn{2}{|c|}{$\leq 40$} \\
\hline & Ward, ICU & $\leq 40$ & $\leq 35$ \\
\hline Hospital & $\begin{array}{l}\text { Operating room, consulting } \\
\text { room }\end{array}$ & \multicolumn{2}{|c|}{$\leq 40$} \\
\hline
\end{tabular}

It can be seen that even if the new railway is on the side where away from the residential area, the minimum distance between the railway and residential area must be determined in accordance with the provisions of the current planning standards, or the noise suppression measures must be taken to meet the GB50118-2010, and the implementation cannot be carried out unless the consent of the local planning administrative department and the stakeholders in the affected area. It must not be thought of simply that it is reasonable have not continue close with residential areas based on existing railway.

\subsection{North Double Track Bridge Scheme}

The railway pass through Lan-Xin high-speed railway under Lijiagou and parallels Lan-Xin railway to the West. The existing Lan-Xin railway needs to be reconstructed. A new frame bridge is built on the existing Lan-Xin railway. The Lan-Xin railway passes through the frame bridge. The Zhong-Lan high-speed railway pass through the frame bridge and cross the Lan-Xin railway on the top of the frame bridge to the north side. The Lan-Xin railway needs to be set with a temporary line transition. The line is located in the north side of the existing Lan-Xin railway.

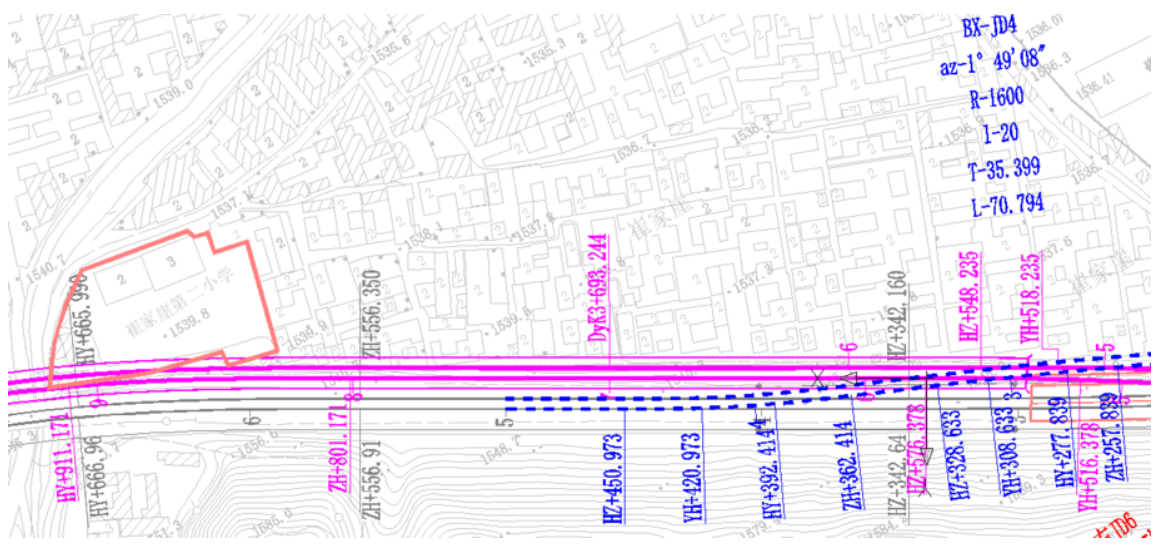

Figure.4 Schematic diagram of bridge on the north side of Lan-Xin railway 
It can be seen from Figure 4, this scheme set the Zhong-Lan high-speed railway in the north side of the existing Lan-Xin railway (near the residential area side), which passes through this area by bridge. The plan is not only closer to the residential area and school on the basis of the existing railway, but also needs to remove the residential buildings and some school walls within the land. According to the content of the previous section, this scheme has a greater impact to residential areas, it is impossible to implement.

\subsection{South Double Track Tunnel (subgrade) Scheme}

The Zhong-Lan high-speed railway pass through the Lan-Xin High Speed Railway under Lijiagou and pass through the mountain to the west by tunnel or subgrade. The railway is located in the south side of the existing Lan-Xin railway.

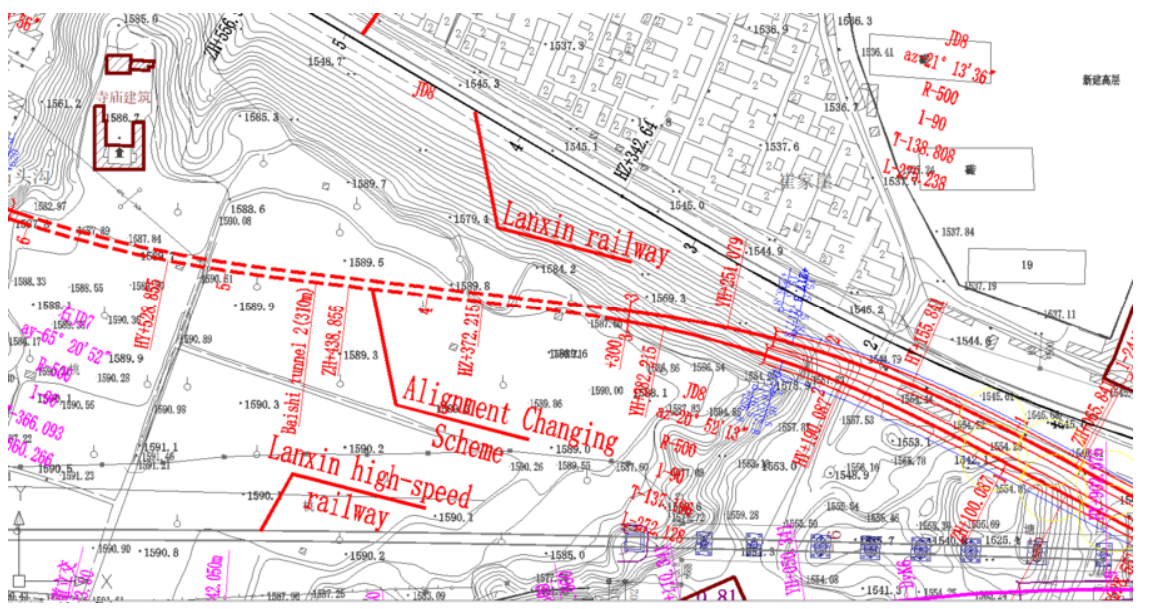

Figure 5. Schematic diagram of subgrade(tunnel) on the south side of Lan-Xin railway

It can be seen from Figure 5, this scheme set the Zhong-Lan high-speed railway on the south of the existing Lan-Xin railway (away from the residential area), which pass through this area by tunnel or subgrade, minimizing the impact on the residential area. At the same time, it is away from the existing Lan-Xin railway and avoid the risk of construction beside the existing railway. In fact, there are 12 versions of the rerouting scheme. In this section, it is only choose typical scheme to explain the impact of environmental protection requirements on the route selection. Finally, the South double line tunnel scheme is recommended.

\section{Impact of Urban Land Intensive on Line Selection}

In the last section, it is analyzed that in terms of environmental protection, the south double track tunnel (subgrade) scheme is the best one. This section will further discuss the advantages and disadvantages of the scheme in terms of urban intensive land use. 
One of the important principles of new railway construction in urban built-up areas is reduce cut city as much as possible, and the route selection in this scheme is located in the middle of the Lan-Xin high-speed railway and Lan-Xin railway. A large parking lot has been built on the land, which is used to park the vehicles for sale in the nearby $4 \mathrm{~S}$ shop, and the canopy was built with steel structure.

If the subgrade scheme is adopted, the maximum excavation depth of $27 \mathrm{~m}$ will cause the width of the upper opening to reach $100 \mathrm{~m}$, even if the retaining structure is adopted, the width of the opening will still reach about $70 \mathrm{~m}$. In this way, not only the project cost will be increased greatly, but also the urban land will be expropriated completely. The land between the Zhong-Lan high-speed railway, Lan-Xin railway and Lan-Xin high-speed railway will lose its use value, resulting in a great waste of urban land resources.

If the tunnel scheme is adopted, the settlement of the foundation at the top of the tunnel will be caused, and the existing buildings in this area need to be compensated, but the tunnel scheme can use the land intensively greatly. The land on the top of tunnel can still be used after foundation treatment.

Therefore, from the perspective of land intensification, it is better to select the line along the wasteland or urban edge for the new railway in the urban built-up area. Judge the future development direction of the city according to the urban master plan, so as to avoid the influence of the line selection on the future development of the city and cut the urban development area. For the whole construction land among the existing transit highways, urban roads, railways and large buildings, the new railway should be parallel to these existing traffic corridors as much as possible to avoid occupying the complete land resources with high use value again.

\section{Influence of other Factors on Line Selection}

\subsection{Fully Consider the Influence of Urban Road Red Line on Route Selection and Bridge Span Layout}

As with the blue line of the city, the urban master plan of a large and medium-sized city has defined the red lines for main roads of the city, which often include the width required for future road reconstruction and expansion. Therefore, at the intersection of the railway and urban road, the bridge span should not be arranged only according to the width of the existing road, but should be arranged in the residential construction and natural resources (Planning) departments, combined with the current situation of the road and the collected data. The bridge layout must meet the needs of the sight triangle of the urban road and the sight distance of parking (meeting vehicles). If it is difficult to set long-span bridges, the urban road can be reconstructed to meet the relevant requirements. 


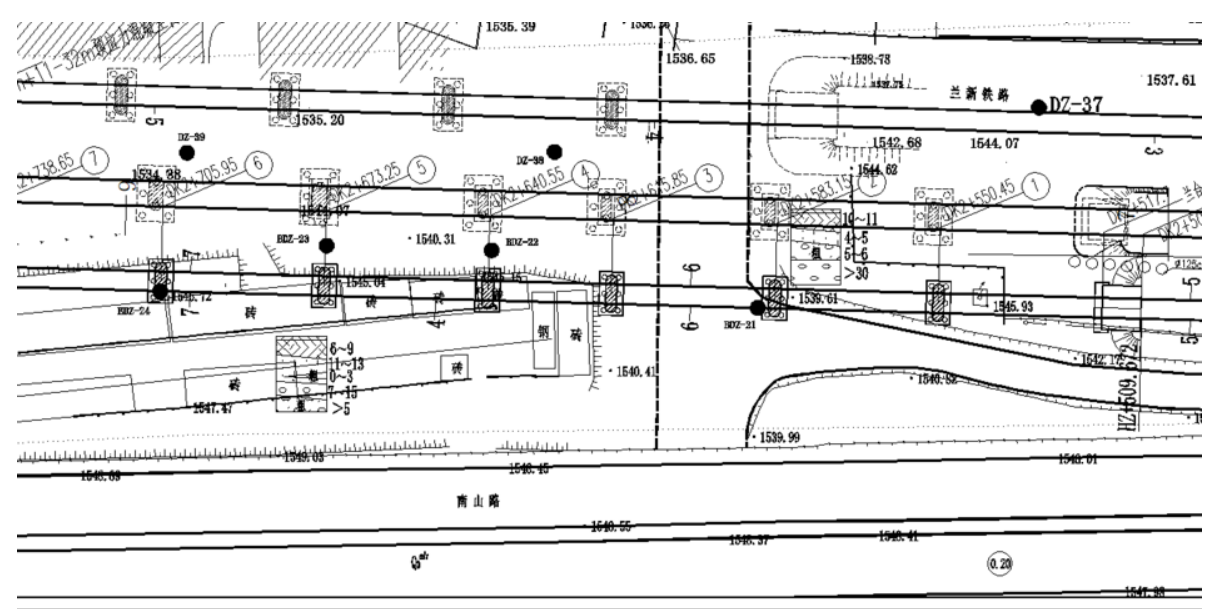

Figure 6. Layout plan of Dujiagou bridge of Zhong-Lan high-speed railway

Taking Dujiagou interchange of Zhong-Lan high-speed railway as an example, the newly built third and fourth line is located in the south of the existing Lan-Xin high-speed railway and the north of municipal Nanshan Road. The 32m T-beam was used to cross Dujiagou road of existing Lan-Xin railway and Lan-Xin high-speed railway.The right ramp from Dujiagou to Nanshan Road meets the requirements of urban road sight distance.

The $32 \mathrm{~m}$ T-beam is also used to cross the Dujiagou road of the Zhong-Lan high-speed railway. Meanwhile, the existing ramp is properly relocated to the south side. The bridge span does not consider the planning of the left ramp from Nanshan Road to Dujiagou. The interchange scheme did not pass the expert review held by the competent department of Lanzhou government. It is required to cross the left (existing) right (planned) ramp and Dujiagou road with long-span at one time. Due to the restrictions of interchange clearance and terrain, it is not suitable to arrange long-span bridge structure in this area, so it is changed to build interchange ramp on the south side of existing Nanshan Road to solve the sight distance problem.

Therefore, in addition to meeting the current needs of the road, the layout of the railway bridge span in the urban built-up area also needs to collect relevant data for comprehensive consideration. After the overpass scheme is determined, the overpass agreement shall be signed with the road authority in time to avoid large engineering changes at later stage.

It should be emphasized that the data collected from department of housing and urban rural development and the planning department are often inconsistent. The former mainly includes the current roads and reconstruction and expansion data, while the latter usually includes the planned roads. Therefore, when arranging the bridge span, it may pay attention to reserving the urban planning road conditions, so as to avoid the unnecessary general measurement due to the bad traffic conditions of the road engineering at later stage. At present, the leading idea of the Ministry of housing and urban rural development for urban road construction is to increase the density of the road network, that is, to increase the density of the Urban Branch Road and improve the service function of the branch road. Therefore, when considering the interchange schemes of the urban expressway, the main road and the secondary road, it is necessary to pay attention to the interchange needs with the Urban Branch Road. 


\subsection{Fully Consider the Influence of Urban Purple Line on Line Selection}

Cities with many cultural relics and rich historical features often have a wide range of purple lines. Article 13 of the measures for the administration of urban purple lines (Order No. 119 of the Ministry of construction of the People's Republic of China) stipulates that: it is forbidden to build buildings, structures and other facilities that damage the traditional appearance of historical and cultural blocks within the scope of urban purple lines; it is forbidden to occupy or destroy the buildings, structures and other facilities determined to be preserved in the protection plan as soon as the planning for the protection of historical and cultural city and historical and cultural block is approved, it shall not be adjusted in principle.

Xi'an, Luoyang and other famous historical and cultural cities have changed the project and made slow progress due to the problem of urban purple line; Dunhuang to Golmud railway has also changed the plan due to the problem of distance from the West thousand Buddha cave. Therefore, it is necessary to collect the urban purple line and pay attention to the impact of the urban purple line during the new railway survey in the urban area. The railway should be far away from the purple line to avoid the damage of the new project to the traditional historical features.

\section{Conclusions and Recommendations}

In order to expound the key points of railway route selection in urban built-up areas systematically, this paper takes Lanzhou railway hub as an example to discuss the impact of environmental protection, urban blue line, purple line, red line and intensive land use on the route selection and the points need to pay attention. The following conclusions are drawn:

(1) It can be conclude that the bridge span layout of Zhong-Lan high-speed railway does not meet the requirements of the planned blue line due to neglecting the urban blue line in the construction drawing design stage and haven't communicate with the water authority in time. The adjustment of bridge span not only causes the increase of project investment, but also seriously restricts the project progress. Therefore, the data of urban blue line must be collected in the stage of location survey of railway projects in urban areas, and communicate with the water authorities should be carried out actively, and the route selection and bridge span layout should be combined with the blue line and opinions of relevant departments.

(2) In the process of Zhong-Lan high-speed railway scheme design, the principle is that the new railway is not closer to the residential area on the basis of the existing railway, but in fact, this design concept is wrong. Even if the new railway is on the side where away from the residential area, the minimum distance between the railway and residential area must be determined in accordance with the provisions of the current planning standards, or the noise suppression measures must be taken to meet the GB50118-2010, and the implementation cannot be carried out unless the consent of the local planning administrative department and the stakeholders in the affected area. It must not be thought of simply that it is reasonable have not continue close with residential areas based on existing railway.

(3) It is recommended to adopt the South double track tunnel scheme of Zhong-Lan high-speed railway. This scheme cross the mountain by tunnel, it occupies small land which can be fully utilized after the treatment of the ground foundation on 
the top of the tunnel. It also will not produce noise pollution to the residential area, at the same time, it can avoid the construction risk near the existing railway.

So new railway in the urban built-up area it is better to select the line along the wasteland or urban edge for the new railway in the urban built-up area. Judge the future development direction of the city according to the urban master plan, so as to avoid the influence of the line selection on the future development of the city and cut the urban development area. For the whole construction land among the existing transit highways, urban roads, railways and large buildings, the new railway should be parallel to these existing traffic corridors as much as possible to avoid occupying the complete land resources with high use value again.

(4) The planned urban road red line's influence have not considered of the Zhong-Lan high-speed railway route selection, which results in that the interchange scheme fails to pass the expert review organized by Lanzhou government, and it is required to cross the left (existing) right (planned) ramp and Dujiagou road with long-span at one time. So in addition to meeting the current needs of the road, the layout of the railway bridge span in the urban built-up area also needs to collect relevant data for comprehensive consideration. After the overpass scheme is determined, the overpass agreement shall be signed with the road authority in time to avoid large engineering changes at later stage.

In the urban areas with many cultural relics and rich historical features, new railway should be built in the survey stage, it is necessary to collect urban purple line data and pay attention to the influence of urban purple line on route selection. The railway should be far away from the purple line to avoid damage to the traditional historical features.

\section{References}

[1] Wang YP. Tentative Study on the solution for the optimization of Hefei railway logistics base. Railway Transport and Economy. 2017, 39(10): 21-25.

[2] China Railway First Survey and Design Institute Group Ltd. General plan of Lanzhou railway terminal,2018.

[3] Dong ZQ. Research on the schemes for leading high speed railways into Baotou railway terminal. Journal of Railway Engineering Society. 2017,34(2): 5-10.

[4] Lu JJ. Coordination of railway hub planning and urban planning. Railway Transport and Economy. 2005,27(10): 4-5.

[5] Dufound H, Gendreau M, Laporte G. Locating a transit line using tabu search. Location Science, 1996,4(1): 1-19.

[6] Bruno G, Gendreau M, Laporte G. A heuristic for the location of a rapid transit line. Computers \& Operations Research. 2002,29(1): 1-12.

[7] Farooq A, et al. Multicriteria evaluation of transport plan for high-speed rail: an application to Beijing-Xiongan. Mathematical Problems in Engineering, 2019.1(2019):1-23.

[8] Code for design of sound insulation of civil buildings(GB50118-2010),Ministry of housing and urban rural development of the people's Republic of China,General Administration of quality supervision, inspection and Quarantine of the people's Republic of China,2010.

[9] Administrative measures for the examination and approval of the preparation of urban master plan,Ministry of housing and urban rural development of the people's Republic of China,2016. 